\title{
The burden and management of anemia in Greek patients with inflammatory bowel disease: a retrospective, multicenter, observational study
}

Kalliopi Foteinogiannopoulou ${ }^{1^{*}}$ (D) Konstantinos Karmiris ${ }^{2}$, Georgios Axiaris ${ }^{3}$, Magdalini Velegraki², Antonios Gklavas ${ }^{4}$, Christina Kapizioni ${ }^{5}$, Charalabos Karageorgos ${ }^{6}$, Christina Kateri ${ }^{7}$, Anastasia Katsoula ${ }^{8}$, Georgios Kokkotis ${ }^{9}$, Evgenia Koureta ${ }^{10}$, Charikleia Lamouri ${ }^{11}$, Panagiotis Markopoulos ${ }^{12}$, Maria Palatianou ${ }^{13}$, Ploutarchos Pastras ${ }^{14}$, Konstantinos Fasoulas ${ }^{15}$, Olga Giouleme ${ }^{8}$, Evanthia Zampeli ${ }^{3}$, Aggeliki Theodoropoulou ${ }^{2}$, Georgios Theocharis ${ }^{14}$, Konstantinos Thomopoulos ${ }^{14}$, Pantelis Karatzas ${ }^{10}$, Konstantinos H. Katsanos ${ }^{11}$, Andreas Kapsoritakis ${ }^{7}$, Anastasia Kourikou ${ }^{6}$, Nikoleta Mathou ${ }^{16}$, Spilios Manolakopoulos ${ }^{6}$, Georgios Michalopoulos ${ }^{5}$, Spyridon Michopoulos ${ }^{3}$, Alexandros Boubonaris ${ }^{17}$, Giorgos Bamias ${ }^{9}$, Vasileios Papadopoulos ${ }^{7}$, George Papatheodoridis ${ }^{10}$, Ioannis Papaconstantinou ${ }^{4}$, loannis Pachiadakis ${ }^{17}$, Konstantinos Soufleris ${ }^{15}$, Maria Tzouvala ${ }^{13}$, Christos Triantos $^{14}$, Eftychia Tsironi ${ }^{12}$, Dimitrios K. Christodoulou ${ }^{11}$ and loannis E. Koutroubakis ${ }^{1}$ on behalf of the Hellenic group for the study of IBD

\begin{abstract}
Background: Anemia is a common extraintestinal manifestation of Inflammatory Bowel Disease (IBD) affecting negatively the patients' quality of life. The aim of this study was to determine the frequency and real-life management of anemia in IBD patients in Greece.

Methods: This study was conducted in 17 Greek IBD referral centers. Demographic, clinical, laboratory, IBD and anemia treatment data were collected and analyzed retrospectively.

Results: A total of 1394 IBD patients [560 ulcerative colitis (UC), 834 Crohn's disease (CD)] were enrolled. Anemia at any time was reported in 687 (49.3\%) patients of whom 413 (29.6\%) had episodic and 274 (19.7\%) had recurrent/ persistent anemia. Anemia was diagnosed before IBD in 45 (6.5\%), along with IBD in $269(39.2 \%)$ and after IBD in 373 (54.3\%) patients. In the multivariate analysis the presence of extraintestinal manifestations $(p=0.0008)$, IBD duration $(p=0.026)$, IBD related surgeries and hospitalizations ( $p=0.026$ and $p=0.004$ accordingly) were risk factors of recurrent/persistent anemia. Serum ferritin was measured in 839 (60.2\%) IBD patients. Among anemic patients, 535 (77.9\%) received treatment. Iron supplementation was administered in 485 (90.6\%) patients, oral in $142(29.3 \%)$ and intravenous in 393 (81\%).
\end{abstract}

\footnotetext{
*Correspondence: drfpopi@hotmail.com

1 Gastroenterology Department, University Hospital of Heraklion, Medical

School University of Crete, P.O. Box 1352, 71110 Heraklion, Crete, Greece

Full list of author information is available at the end of the article
} permitted by statutory regulation or exceeds the permitted use, you will need to obtain permission directly from the copyright holder. To view a copy of this licence, visit http://creativecommons.org/licenses/by/4.0/. The Creative Commons Public Domain Dedication waiver (http://creativecommons.org/publicdomain/zero/1.0/) applies to the data made available in this article, unless otherwise stated in a credit line to the data. 
Conclusions: The frequency of anemia in IBD patients, followed at Greek referral centers, is approximately 50\%. Development of recurrent/persistent anemia may be observed in $20 \%$ of cases and is independently associated with the presence of extraintestinal manifestations, IBD duration, IBD related surgeries and hospitalizations. Anemia treatment is administered in up to $4 / 5$ of anemia IBD patients with the majority of them receiving iron intravenously.

Keywords: Anemia, Crohn's disease, Iron, Iron deficiency, Ulcerative colitis

\section{Background}

Inflammatory bowel diseases (IBD) are chronic inflammatory disorders that encompass mainly Crohn's disease (CD) and ulcerative colitis (UC). The incidence of IBD in Greece is about 10 per 100,000 inhabitants per year (6.18.9 for UC and 2.75-3.0 for CD) (1).

IBD patients often present extra-intestinal manifestations with anemia to be the most common (2). There is a wide range of the reported prevalence of anemia in IBD possibly reflecting the heterogeneity of the study population (in-hospital or out-patient patients), of the severity of IBD, of the IBD treatment (5-ASA, anti-TNFs etc.) as well as of the time point of the assessment (at diagnosis or during the course of IBD).

Anemia is typically classified into iron deficiency anemia (IDA), anemia of chronic disease (ACD) and anemia due to $\mathrm{B} 12$ or folic acid deficiency based on the ECCO guidelines. However, there is a difficulty in determining the exact type of anemia in IBD patients, since chronic blood loss, inflammation, medication toxicity, surgical procedures, malabsorption or even malnutrition can be present at the same time in an IBD patient $(3,4)$. Another classification of anemia that has been suggested is based on the course of anemia as episodic (if presented only once), recurrent (if $\mathrm{Hb}$ was restored for a period of time and then dropped below normal again) and persistent anemia (if all available values of $\mathrm{Hb}$ were below normal) (5). Most of the anemia's symptoms are very common (fatigue, dizziness, dyspnea, cold skin, glossitis, hair loss) while others (impairment of cognitive function, restless legs syndrome) are less frequently seen. Anemia is of a great importance not only because of its high frequency but also because of the negative impact on work productivity and quality of life $(6,7)$. It is well established that anemia is positively correlated with the IBD activity, risk of surgery and prolonged hospitalization but recent studies even correlate anemia with $\operatorname{IBD}$ severity $(5,8)$.

Although anemia diagnosis in IBD is often neglected, anemia treatment should be given to all patients with low hemoglobin $(\mathrm{Hb})$ particularly in the form of iron replacement, since ID is the most frequent cause of anemia in IBD. Recent data suggest that intravenous iron administration is safe, well tolerated and efficient particularly when it comes to patients with severe anemia
$(\mathrm{Hb}<10.0 \mathrm{~g} / \mathrm{dl})$, intolerant or non-responding to oral iron supplementation, and those with active disease (9).

The aims of this study were: (i) to capture the frequency of anemia in a cohort of IBD patients followed at Greek referral centers, (ii) to investigate for potential risk factors for anemia and (iii) to register real life management of anemia.

\section{Methods}

This is a retrospective, multicenter observational study conducted in 17 IBD centers in Greece. Patients 18-80 years, with confirmed diagnosis of $\mathrm{UC}$ or $\mathrm{CD}$ for at least 3 months and having attended $>1$ IBD clinic visits with available lab results permitting the evaluation of anemia were included. All patients with known comorbidities that could cause anemia independently (congestive heart failure, chronic kidney failure, active cancer, cirrhosis, Mediterranean anemia trait etc.) as well vegetarian patients were excluded. Gender, age at IBD diagnosis, disease duration at study entry for nonanemic patients and at first presentation of anemia for anemic patients, disease location and behavior for $\mathrm{CD}$ and disease extent for UC according to Montreal Classification, smoking habits, extra-intestinal manifestations, IBD-related hospitalizations and surgeries (right hemicolectomy, enterectomy, colectomy), IBD treatment and C-reactive protein (CRP) at entry for non-anemic and at first presentation of anemia for anemic patients were recorded in a pre-defined standardized report form. Clinical disease activity was evaluated with HarveyBradshaw score (HBI) and Simple Clinical Colitis Score (SCCAI) for CD and UC respectively and Short Inflammatory Bowel Disease Questionnaire (SIBDQ) was used to evaluate quality of life, at the study entry. Data was extracted retrospectively from the local IBD databases of 17 Greek centers for a period of 12 months (from February 2019 until January 2020). There has not been adopted a special policy of checking either the hemoglobin or the general blood count, specifically for this study protocol and the frequency of the lab tests was according to the clinical practice (usually every 3 months for those receiving biologics, immunomodulators or combination treatment and every 6 months for those on exclusively non-immunosuppressive treatment). 
Anemia was defined according to World Health Organization (WHO) criteria when hemoglobin $(\mathrm{Hb})$ was below $12.0 \mathrm{~g} / \mathrm{dl}$ for non-pregnant women and below $13.0 \mathrm{~g} / \mathrm{dl}$ for men (7). Anemia was characterized as episodic, if presented only once, recurrent, if $\mathrm{Hb}$ was restored for a period of time and then dropped below normal again, and persistent if all available values of $\mathrm{Hb}$ were below normal. Treatment of anemia was also captured. Hemopoietic response was also evaluated, in patients treated with iron, where there were available laboratory data. Responders to the treatment of anemia were considered those with an increase of $\mathrm{Hb}$ by $>2 \mathrm{~g} /$ $\mathrm{dl}$ or when $\mathrm{Hb}$ returned to normal levels within 4 weeks after iron administration $(11,12)$.

\section{Statistical analysis}

Data are presented either as mean $( \pm S D)$ for normally distributed variables or as median (IQR, range) for nonnormally distributed. Categorical data were analyzed with the chi-square or Fischer's exact test. Independent factors associated with persistent/recurrent anemia were assessed by multivariate analysis based on binary logistic regression analysis and including those covariates with $\mathrm{p}<0.10$ in the univariate analysis. Odds ratios (OR) were calculated with $95 \%$ confidence intervals (CI). Tests were two-sided and $\mathrm{P}$ values $<0.05$ were considered to be statistically significant. The statistical program used was MedCalc (MedCalc Software Ltd, Belgium).

\section{Results}

A total of 1394 patients met the inclusion criteria and formed the study population. Of those, 560 patients with UC and 834 with CD were included. Demographics and clinical characteristics of the population under investigation are shown in Table 1.

The median age at diagnosis was 32 (IQR 24, 22-46) years for CD and 35 (IQR 22, 24-46) years for UC. Females in CD were 389 (46.6\%) whereas in UC were 246 (43.9\%). Active smokers were more in CD (39.5\%) than in UC $(20 \%)(\mathrm{p}<0.0001)$. Extra-intestinal manifestations,

Table 1 Demographics and clinical characteristics of study population $(\mathrm{N}=1394)$

\begin{tabular}{|c|c|c|c|}
\hline & Total IBD & CD & UC \\
\hline Number (\%) & $1394(100)$ & $834(59.8)$ & $560(40.2)$ \\
\hline Median diagnosis age (years, range) & $33(23-46)$ & $32(22-46)$ & $35(24-46)$ \\
\hline Sex (females, \%) & $635(45.6)$ & $389(46.6)$ & $246(43.9)$ \\
\hline Median IBD duration ${ }^{\mathrm{a}}$ (years, range) & $3(1-9)$ & $3(1-8.25)$ & $3(1-10)$ \\
\hline Active smokers (\%) & $442(31.7)$ & $330(39.5)$ & $112(20)$ \\
\hline Ex-smokers (\%) & $366(26.2)$ & $189(22.7)$ & $177(31.6)$ \\
\hline Never smoked (\%) & $586(42.1)$ & $315(37.8)$ & $271(48.4)$ \\
\hline Median BMI (range) & $24.5(21.5-27.8)$ & $24.3(21.5-27.9)$ & $24.7(21.6-27.7)$ \\
\hline \multicolumn{4}{|l|}{ Montreal classification for UC } \\
\hline Proctitis (E1, \%) & & & $63(11.25)$ \\
\hline Left sided colitis (E2, \%) & & & $237(42.5)$ \\
\hline Extensive colitis (E3,\%) & & & $259(46.25)$ \\
\hline \multicolumn{4}{|l|}{ Montreal classification for CD } \\
\hline I nflammatory (B1,\%) & & $515(61.8)$ & \\
\hline Stricturing (B2, \%) & & $190(22.8)$ & \\
\hline Penetrating (B3, \%) & & $129(15.4)$ & \\
\hline Perianal $(p, \%)$ & & $165(19.8)$ & \\
\hline Ileum (L1, N, \%) & & $376(45.0)$ & \\
\hline Colon (L2, N, \%) & & $79(9.5)$ & \\
\hline Ileocolonic (L3, N, \%) & & $380(45.5)$ & \\
\hline Upper GI (L4, N, \%) & & $114(13.7)$ & \\
\hline EIMs (\%) & $469(33.6)$ & $325(38.9)$ & $144(25.7)$ \\
\hline Anti-TNFs $(N, \%)$ & $692(49.6)$ & $495(59.4)$ & $197(35.2)$ \\
\hline Immunomodulators (N, \%) & $529(37.9)$ & $380(45.6)$ & $149(26.6)$ \\
\hline Other biologics $(\mathrm{N}, \%)$ & $230(16.5)$ & $131(15.7)$ & $99(17.7)$ \\
\hline IBD-related surgery (N, \%) & $176(12.6)$ & $156(18.7)$ & $20(3.6)$ \\
\hline
\end{tabular}

UC, Ulcerative Colitis; CD, Crohn's Disease; BMI, Body Mass Index; IBD, Inflammatory Bowel Disease; GI, Gastrointestinal; EIMs, Exta-intestinal Manifestations; Anti-TNFs, Anti-Tumor Necrosis Factors

${ }^{\text {a }}$ At first presentation of anemia for anemic patients or at entry for non-anemic patients 
other than anemia, were present in 325 (38.9\%) CD and $144(25.7 \%)$ UC patients $(\mathrm{p}<0.0001)$. A history of major IBD-related surgery was reported by $176(12.6 \%)$ patients, 156 (18.7\%) with CD and 20 (3.6\%) with UC $(\mathrm{p}<0.0001)$. Anti-TNFs exposed were more in $\mathrm{CD}$ (59.4\%) than in UC (35.2\%) and use of immunomodulators (Azathioprine, Methotrexate, 6-Mercaptopurine) was also more frequent in CD than in UC patients $(45.6 \%$ vs $26.6 \%$ ) (both with $\mathrm{p}<0.0001$ ). The patients on newer biologics (Vedolizumab and Ustekinumab) were 230 (151 and 79 accordingly) are referred together as "other biologics" on the Tables (Table 1, 2, 4). Regarding Tofacitinib, at that timepoint when the study recruited patients, was not available in Greece.
In total, 687/1394 (49.3\%) had a diagnosis of anemia. Anemia was initially detected more than one year before IBD in 45 patients $(6.5 \%, 31 \mathrm{CD}$ and $14 \mathrm{UC})$, concurrently with IBD or less than 1 year before in 269 (39.2\%, $156 \mathrm{CD}$ and $113 \mathrm{UC}$ ) and after IBD diagnosis in 373 (54.3\%, 236 CD and 137 UC) (Fig. 1). The study population was divided into three groups: non-anemic patients at any time (group A), episodically anemic (group B), and recurrently or persistently anemic patients (group C) (Table 2). There were more males than females in group A $(61.1 \%$ vs $38.9 \%, p<0.0001)$ whereas there was no significant difference in the other two groups regarding gender. $C D$ was the more frequent diagnosis in groups $B$ and $\mathrm{C}(\mathrm{p}=0.0039$ and $\mathrm{p}=0.0043)$.

Table 2 Patients' characteristics according to their anemia history $(N=1394)$

\begin{tabular}{|c|c|c|c|c|}
\hline & $\begin{array}{l}\text { Group A } \\
\text { No anemia }\end{array}$ & $\begin{array}{l}\text { Group B } \\
\text { Episodic anemia }\end{array}$ & $\begin{array}{l}\text { Group C } \\
\text { Recurrent/persistent anemia }\end{array}$ & $\mathbf{P}$ \\
\hline Number (\%) & $707(50.7)$ & $413(29.6)$ & $274(19.7)$ & \\
\hline Males/females (\%) & $432 / 275(61.1 / 38.9)$ & 208/205 (50.4/49.6) & $119 / 155(43.4 / 56.6)$ & $<0.0001$ \\
\hline CD/UC (\%) & $412 / 295(58.3 / 41.7)$ & 236/177 (57.1/42.9) & $186 / 88(67.9 / 32.1)$ & 0.0089 \\
\hline Median IBD duration ${ }^{\mathrm{a}}$ (years, range) & $5(2-11)$ & $1(0-4)$ & $2(0-8)$ & $<0.0001$ \\
\hline Median diagnosis age (years, range) & $35(24-46)$ & $32(23-45.5)$ & $30(21-46)$ & $<0.0001$ \\
\hline Active smokers (\%) & $238(33.7)$ & $121(29.3)$ & $83(30.3)$ & 0.2356 \\
\hline Ex-smokers (\%) & $205(29)$ & $96(23.2)$ & $64(23.3)$ & 0.0435 \\
\hline Never smoked (\%) & $264(37.3)$ & $195(47.2)$ & $127(46.4)$ & 0.0008 \\
\hline Median BMI (range) & $25.2(22.5-28.6)$ & $24.2(21.3-27.25)$ & $23.5(20.7-27.0)$ & $<0.0001$ \\
\hline \multicolumn{5}{|l|}{ Montreal classification for UC } \\
\hline Proctitis (E1,\%) & $53(18)$ & $7(3.9)$ & $3(3.4)$ & $<0.0001$ \\
\hline Left sided colitis $(E 2, \%)$ & $129(43.7)$ & $75(42.4)$ & $33(37.5)$ & 0.5834 \\
\hline Extensive colitis $(\mathrm{E} 3, \%)$ & $113(38.3)$ & $95(53.7)$ & $52(59.1)$ & 0.0002 \\
\hline \multicolumn{5}{|l|}{ Montreal classification for CD } \\
\hline Inflammatory (B1, \%) & $272(66)$ & $154(65.2)$ & $89(47.8))$ & $<0.0001$ \\
\hline Stricturing (B2, \%) & $84(20.4)$ & $45(19.1)$ & $61(32.8)$ & 0.6111 \\
\hline Penetrating (B3, \%) & $56(13.6)$ & $36(15.2)$ & $36(19.4)$ & 0.6050 \\
\hline Perianal $(p, \%)$ & $80(19.4)$ & $42(17.8)$ & $42(22.5)$ & 0.4901 \\
\hline Ileum (L1, N, \%) & $209(50.7)$ & $97(41.1)$ & $70(37.6)$ & 0.0037 \\
\hline Colon (L2, N, \%) & $35(8.5)$ & $23(9.7)$ & $20(10.8)$ & 0.6575 \\
\hline Ileocolonic (L3, N, \%) & $168(40.8)$ & $116(49.2)$ & $96(51.6)$ & 0.0191 \\
\hline Upper GI (L4, N, \%) & $46(11.2)$ & $41(17.4)$ & $27(14.5)$ & 0.0766 \\
\hline Disease activity_clinically judged & $176(24.9)$ & $238(57.6)$ & $145(52.9)$ & $<0.0001$ \\
\hline EIMs (\%) & $199(28.1)$ & $138(33.4)$ & $131(47.8)$ & $<0.0001$ \\
\hline Anti-TNFs (N, \%) & $261(36.9)$ & $242(58.6)$ & $188(68.6)$ & $<0.0001$ \\
\hline Immunomodulators (N, \%) & $225(31.8)$ & $175(42.4)$ & $129(47.1)$ & $<0.0001$ \\
\hline Other biologics $(\mathrm{N}, \%)$ & $82(11.6)$ & $90(21.8)$ & $58(21.2)$ & 0.0624 \\
\hline IBD-related surgery (N, \%) & $61(8.6)$ & $51(12.3)$ & $64(23.4)$ & $<0.0001$ \\
\hline
\end{tabular}

Group A never anemic patients, Group B episodically anemic patients, Group C recurrently/persistently anemic patients

UC, Ulcerative Colitis; CD, Crohn's Disease; BMI, Body Mass Index; IBD, Inflammatory Bowel Disease; GI, Gastrointestinal; EIMs, Exta-intestinal Manifestations; Anti-TNFs, Anti-Tumor Necrosis Factors

${ }^{\text {a }}$ At first presentation of anemia for anemic patients or at entry for non-anemic patients 


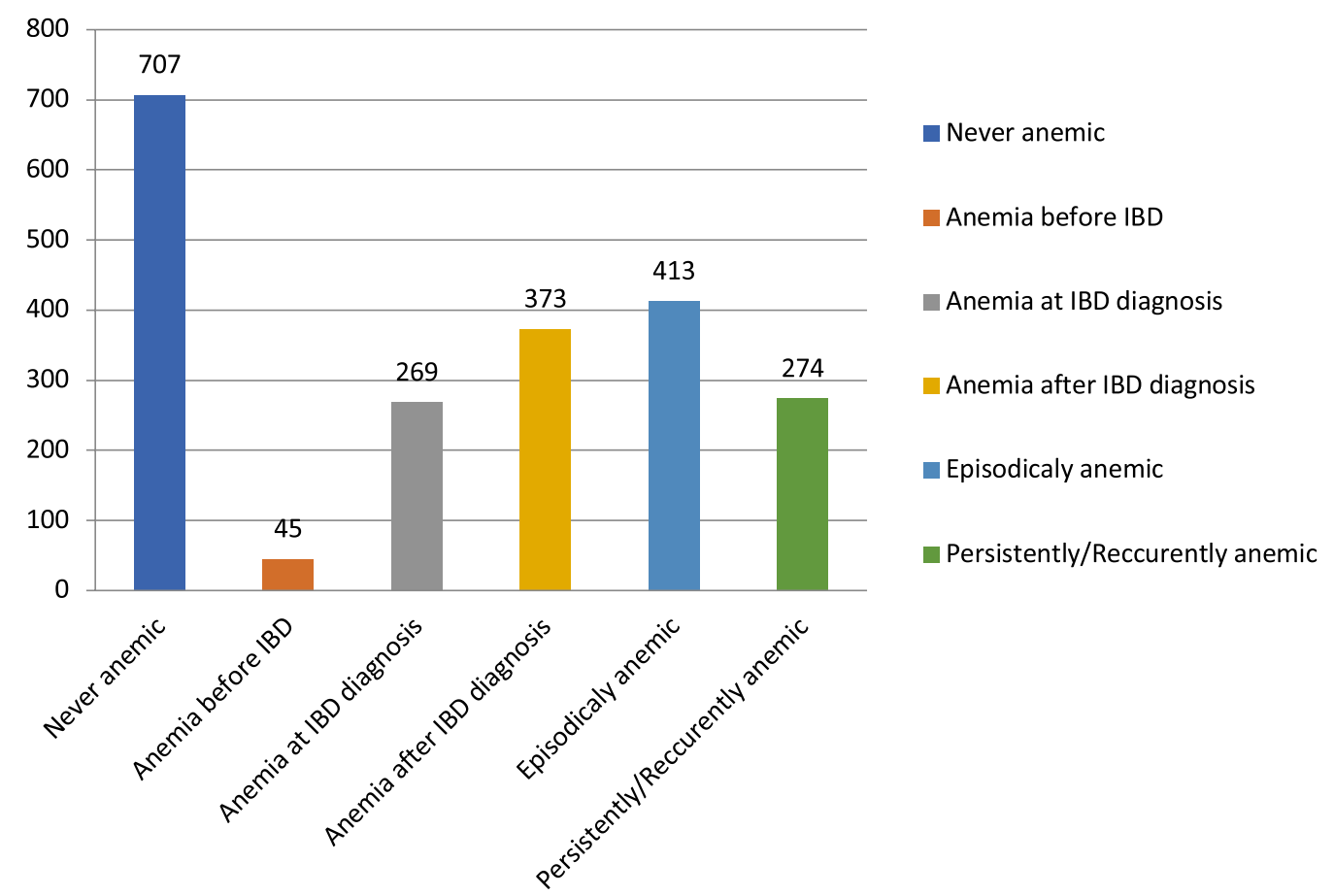

Fig. 1 Time point and status of Anemia in IBD patients $(N=1394)$

Median age at diagnosis, median disease duration and median BMI were higher in group A compared to the other two groups (all with $\mathrm{p}<0.0001$, Table 2 ). UC proctitis was more common and extensive colitis less common in group $A(p<0.0001$ and $p=0.0002$ respectively). In $\mathrm{CD}$, patients non-stricturing non-penetrating phenotype (B1) was more common in group A $(\mathrm{p}<0.0001)$ as well as ileal (L1) disease $(p=0.0037)$ whereas ileocolonic disease (L3) was more common in group C ( $\mathrm{p}=0.0191$, Table 2$)$.

Clinically judged active disease was more frequently seen in groups $B$ and $C(p<0.0001)$. Median CRP levels as well as median HBI (for CD) and SCCAI (for UC) were significantly higher in groups B and C (Table 3). Quality of life as measured with SIBDQ was worse in groups $B$ and $C(p<0.0001)$. Furthermore, patients in these groups were more often under treatment with anti-TNFs or immunomodulators $(\mathrm{p}<0.0001)$. IBD-related surgeries were also more often among anemic patients $(\mathrm{p}<0.0001)$.

In the univariate analysis, persistent/recurrent anemia was found to be associated with $\mathrm{CD}$ diagnosis [OR 1.59 (1.16-2.19), $\mathrm{p}=0.0044$ ], median disease duration [1.03 (1.01-1.05), $\mathrm{p}=0.0100]$, penetrating or stricturing CD [2.07 (1.40-3.07), $\mathrm{p}=0.0003]$, presence of EIMs [1.82 (1.33-2.49), $\mathrm{p}=0.0002]$ use of anti-TNF [1.53

Table 3 Disease activity in IBD anemic (Group B and C) and non-anemic patients (Group A)

\begin{tabular}{|c|c|c|c|}
\hline Characteristics & $\begin{array}{l}\text { Anemic patients } \\
\text { Group } B \text { and } C(N=687)\end{array}$ & $\begin{array}{l}\text { Non-anemic patients } \\
\text { Group } A(N=707)\end{array}$ & $\mathrm{p}$ \\
\hline Disease activity (clinically judged)a (\%) & $382(55.6 \%)$ & $176(24.9 \%)$ & $<0.0001$ \\
\hline Median CRPa mg/dl & $2.00(0.50-7.00)$ & $0.40(0.14-1.3)$ & $<0.0001$ \\
\hline Median SIBDQ & $50(39-60)$ & $61(51-67)$ & $<0.0001$ \\
\hline Median $\mathrm{HBl}^{\mathrm{a}}$ & $5(3-7)$ & $3(1-4)$ & $<0.0001$ \\
\hline Median SCCAI ${ }^{a}$ & $5(3-8)$ & $1(0-4)$ & $<0.0001$ \\
\hline Median Ferritin ${ }^{\mathrm{a}} \mathrm{ng} / \mathrm{ml}$ & $23.03(10-65.9)$ & $70(39-113.2)$ & $<0.0001$ \\
\hline
\end{tabular}

Group A never anemic patients, Group B episodically anemic patients, Group C recurrently/persistently anemic patients CRP, C-Reactive Protein; SIBDQ, Simple Inflammatory Bowel Disease Questionnaire; HBI, Harvey-Bradshaw Index; SCCAl, Simple Colitis Activity Index ${ }^{\text {a }}$ At entry 
(1.11-2.12), $\mathrm{p}=0.0090]$, IBD related hospitalizations [2.39 (1.56-3.66), $\mathrm{p}=0.0001]$ and IBD related surgeries [2.15 (1.43-3.23), $\mathrm{p}=0.0002]$ (Table 4). In the multivariate analysis, parameters that remained significantly associated with persistent/recurrent anemia were median disease duration [1.03 (1.00-1.05), $\mathrm{p}=0.0259]$, presence of EIMs [1.79 (1.27-2.52), $\mathrm{p}=0.0008]$, IBD related hospitalizations [1.96 (1.25-3.09), $\mathrm{p}=0.0035]$, and IBD related surgeries [1.73 (1.07-2.78), $\mathrm{p}=0.0257]$ (Table 4).

Anemia and iron status were mainly assessed with $\mathrm{Hb}$ and ferritin measurement. Ferritin value was available in $839 / 1394$ patients $(60.2 \%)$ and the median value was $43 \mathrm{ng} / \mathrm{ml}$ (IQR 76.7, 13-89.7). Moreover, ferritin was measured in 523 of the $687(76.1 \%)$ anemic patients [median value $23 \mathrm{ng} / \mathrm{ml}$ (IQR 55.9, 10-65.9)]. Ferritin below $30 \mathrm{ng} / \mathrm{ml}$ was detected in 377 patients $(72 \%)$ [median value $8 \mathrm{ng} / \mathrm{ml}$ (IQR $8,7-17$ )] whereas ferritin above $30 \mathrm{ng} / \mathrm{ml}$ and below $100 \mathrm{ng} / \mathrm{ml}$ with CRP above $1 \mathrm{mg} / \mathrm{dl}$ was measured in 61 patients (11.7\%) [median value $55.2 \mathrm{ng} / \mathrm{ml}$ (IQR 28.5, 41-69.5)] which is, according to the ECCO guidelines, compatible with Iron Deficiency Anemia (IDA). Furthermore, anemia of chronic disease (ferritin $>100 \mathrm{ng} / \mathrm{ml}$ ) was detected in 85 patients $(16.3 \%)$ [median value $176 \mathrm{ng} / \mathrm{ml}$ (IQR 118, 134.8-252.8)].

From the 687 anemic IBD patients, 535 (77.9\%, 327 CD, 208 UC) received treatment for their anemia. The vast majority $(485 / 535,90.6 \%)$ were treated with iron supplementation either as an oral in 142 (29.3\%) or as an intravenous formulation in $393(81 \%)$ with a small percentage of patients having received both successively. Of those received iron intravenously, 351 (89.3\%) responded, whereas $77(54.2 \%)$ responded of those received per os iron. Thirty one out of the 142 patients $(21.8 \%)$ that received iron orally presented with adverse events (mostly gastrointestinal symptoms such as abdominal pain and constipation) that eventually led to cessation of the treatment. On the other hand, 31/393 patients $(7.9 \%)$ that iron was given intravenously experienced adverse events during infusion (allergic reactions, skin rash) and 11/393 (2.8\%) post infusion (headache, dizziness, hypophosphatemia). B12 vitamin was administered in $113(21.1 \%)$ and folic acid in $182(33.9 \%)$ patients based on laboratory findings compatible with deficiency. Sixtyeight patients (12.7\%) needed blood transfusion. More details for the treatment of anemia are shown in Table 5.

\section{Discussion}

The present study showed that the frequency of anemia in Greek IBD patients followed at tertiary referral centers is $49.3 \%$ meaning that almost half of those patients experience anemia, which is similar to previous reports from other countries $(2,13-16)$. Anemia was present more frequently in $\mathrm{CD}$ patients and in females which is also in accordance to other studies $(13,15,17)$. It is of notice that there were few patients $(6.5 \%)$ with anemia diagnosed more than one year before IBD diagnosis, whereas anemia was diagnosed at IBD diagnosis or less than one year before in $39.2 \%$ of the patients. In newly diagnosed IBD patients of a population-based inception cohort the prevalence of anemia has been reported to be $48.8 \%$ for

Table 4 Risk factors for persistent/recurrent anemia (group C)

\begin{tabular}{|c|c|c|c|c|}
\hline Risk factors & $\begin{array}{l}\text { Univariate analysis } \\
\text { OR }(95 \% \mathrm{Cl})\end{array}$ & $P$ & $\begin{array}{l}\text { Multivariate analysis } \\
\text { OR }(95 \% \mathrm{Cl})\end{array}$ & $\mathbf{P}$ \\
\hline Female sex & $1.32(0.97-1.79)$ & 0.0804 & $0.78(0.56-1.10)$ & 0.1555 \\
\hline CD diagnosis & $1.59(1.16-2.19)$ & 0.0044 & $0.77(0.54-1.10)$ & 0.1519 \\
\hline Median IBD duration & $1.0304(1.01-1.05)$ & 0.0100 & $1.03(1.00-1.05)$ & 0.0259 \\
\hline Median diagnosis age & $0.9971(0.99-1.01)$ & 0.5563 & & \\
\hline Active smokers & $1.04(0.75-1.45)$ & 0.8113 & & \\
\hline CRP $>3 \mathrm{mg} / \mathrm{dl}$ & $1.11(0.79-1.56)$ & 0.5512 & & \\
\hline Extensive colitis & $1.28(0.76-2.14)$ & 0.3568 & & \\
\hline Penetrating or stricturing CD & $2.07(1.40-3.07)$ & 0.0003 & & \\
\hline Ileocolonic & $1.09(0.74-1.61)$ & 0.6464 & & \\
\hline EIMs & $1.82(1.33-2.49)$ & 0.0002 & $1.79(1.27-2.52)$ & 0.0008 \\
\hline Major disease surgeries & $2.15(1.43-3.23)$ & 0.0002 & $1.73(1.07-2.78)$ & 0.0257 \\
\hline IBD hospitalizations ${ }^{\mathrm{a}}$ & $2.39(1.56-3.66)$ & 0.0001 & $1.96(1.25-3.09)$ & 0.0035 \\
\hline Immmunomodulators & $1.20(0.89-1.64)$ & 0.2346 & & \\
\hline Anti-TNF any time & $1.53(1.11-2.12)$ & 0.0090 & $0.79(0.55-1.14)$ & 0.2062 \\
\hline Other biologics at any time & $1.48(0.82-2.68)$ & 0.1944 & & \\
\hline
\end{tabular}

CD, Crohn's Disease; IBD, Inflammatory Bowel Disease; CRP, C-Reactive Protein; EIMs, Exta-intestinal Manifestations; Anti-TNFs, Anti-Tumor Necrosis Factors

${ }^{\text {a }}$ IBD hospitalizations $\mathrm{n}=5$ the last 5 years 
Table 5 Treatment of anemic IBD patients $(\mathrm{N}=687)$

\begin{tabular}{|c|c|c|c|c|}
\hline & Anemia total $(\mathrm{N}=687)$ & Episodic anemia Group B $(\mathrm{N}=413)$ & $\begin{array}{l}\text { Recurrent/Persistent } \\
\text { anemia } \\
\text { Group C }(\mathrm{N}=274)\end{array}$ & $\mathbf{P}$ \\
\hline Anemia treatment (\%) & $535(77.9)$ & $300(72.6)$ & $235(85.8)$ & $<0.0001$ \\
\hline CD/UC (\%) & $327 / 208(61.2 / 38.8)$ & 167/133 (55.7/44.3) & 160/75 (68.1/31.9) & \\
\hline Iron Administration (\%) & $485(90.6)$ & $286(95.3)$ & $213(90.6)$ & \\
\hline Iron PO/IVa (\%) & $142 / 392(29.3 / 81)$ & $72 / 214(25.2 / 75)$ & 70/178 (32.9/83.6) & \\
\hline B12 Administration (\%) & $113(21.1)$ & $48(16)$ & $65(27.6)$ & 0.0014 \\
\hline $\begin{array}{l}\text { Folic acid Administration }{ }^{b} \\
(\%)\end{array}$ & $182(33.9)$ & $80(26.7)$ & $102(43.4)$ & $<0.0001$ \\
\hline Blood Transfusion (\%) & $68(12.7)$ & $36(12)$ & $32(13.6)$ & 0.0061 \\
\hline \multicolumn{5}{|c|}{ Group A never anemic patients, Group B episodically anemic patients, Group C recurrently/persistently anemic patients } \\
\hline $\begin{array}{l}\text { a Patients who were initially t } \\
\text { discontinuation of the oral fo }\end{array}$ & $\begin{array}{l}\text { eated with oral iron, were sub } \\
\text { mulation }\end{array}$ & equently treated with intravenous iron due to either la & onse or adverse events $t$ & \\
\hline
\end{tabular}

CD and $20.2 \%$ for UC (18). Data on the prevalence of anemia before IBD diagnosis is limited (19).

Anemia was found to be episodic (presented once) in $29.6 \%$ and persistent/recurrent in $19.7 \%$ of the patients. Recurrent/persistent is considered the most serious type of anemia in IBD since it has been associated with severe and disabling disease (5). In our study recurrent/ persistent anemia was found to be significantly and independently associated with disease duration, presence of EIMs, history of major IBD related surgeries and IBD related hospitalizations ( $n=5$ the last 5 years). It is of notice that EIMs (other than anemia) were found to be strongly correlated with the development of persistent/ recurrent anemia $(\mathrm{p}=0.0008)$. Even though anemia itself is one of the most common EIM, it seems that the presence of EIMs (arthritic, skin etc.) could independently be a causative factor for anemia of chronic disease, which is a possible explanation for the above-mentioned strong association between anemia and EIMs. On the other hand, both anemia and EIMs have been reported to be associated with worse disease outcome and severe disease (20).

There is a known association between IBD activity and the presence of anemia (21) something that is in accordance with our results since anemic patients had clinically judged active IBD more often than non-anemic patients. Moreover, median CRP as well as median HBI (for CD) and median SCAAI (for UC) were higher and median IBDQ was lower in patients with anemia. The IBD activity either expressed by clinical judgment or by clinical scores (HBI, SCAAI), accompanied by patients' reported outcomes (IBDQ) reflects a snapshot of a particular moment during disease course. On the other hand, the IBD severity is a wider term incorporating the overall disabling course of the disease with worst outcome, including surgeries frequent hospitalizations etc. Recent reports (5) and the present study support that persistent or recurrent anemia correlates with more aggressive or disabling disease in patients with IBD.

Anemia in IBD patients is considered to be often neglected during the course and treatment of the primary disease, since according to literature review $68.6 \%$ of the anemic UC patients in USA were not further investigated (with ferritin etc.) and even $25 \%$ of IDA IBD patients remained untreated (22). Furthermore, in Switzerland anemia treatment (iron, B12 administration etc.) occurred only in $40 \%$ of patients in private practice and $43 \%$ in University Hospitals (23). On the other side, this study showed that the majority of the anemic IBD patients $(77.9 \%)$ received proper treatment. In this context, most of the patients $(90.6 \%)$ received iron supplementation with $81 \%$ of them receiving iron intravenously. This could be partially attributed to the fact that our study was conducted in referral centers and may not be representative of the real practice in the general IBD population. Our findings are in contrast with earlier studies in Germany (24) and other European countries, in which most of the IBD anemic patients (92\%) are treated with iron, but in the vast majority (67\%) with oral and only $28 \%$ with intravenous formulations (25). An exception to this strategy constitutes Sweden and Switzerland, where iron supplementation was intravenously administered in $72 \%$ and $52 \%$ accordingly. In the present study ferritin was measured in $60.2 \%$ of the study population and in $76.1 \%$ of the anemic patients. This percentage is higher than what was previously referred in the literature (22) and even better than what is recorded in pediatric IBD patients. Although a more meticulous approach is 
expected in pediatric patients, Miller et al. mentioned ferritin measurement only 1 out of 5 anemic pediatric IBD patients (26).

Currently there are no pre-existing data for the frequency, diagnosis and treatment of anemia in Greek IBD patients. Anemia and iron status are mainly assessed with $\mathrm{Hb}$ and ferritin since measurement of transferrin saturation (TSAT) or other blood markers of anemia are not widely available in the everyday clinical practice in Greece. On the contrary TSAT was available in $61 \%$ of the anemic patients in the study of Blumenstein et al. in Germany (24) whereas in other studies this percentage reached $25 \%$ (3). Our findings demonstrate that intravenous iron is implemented more frequently compared to oral administration in IBD patients in Greece. This is in contrast with previous European studies something probably attributed to the fact that these were conducted some years ago and before the development of recent guidelines.

According to ECCO guidelines screening for anemia should be implemented every 6 to 12 months for patients in remission or mild disease and at least every 3 months in those with active disease. Furthermore, a ferritin threshold of $30 \mathrm{ng} / \mathrm{ml}$ for patients with inactive disease and of $100 \mathrm{ng} / \mathrm{ml}$ for patients with active IBD with raised inflammation markers such as CRP has been proposed for the diagnosis of IDA. Moreover, in the presence of inflammation, the diagnostic criteria for ACD are serum ferritin $>100 \mathrm{ng} / \mathrm{ml}$ and $\mathrm{TSAT}<20 \%$. If serum ferritin level is between 30 and $100 \mathrm{ng} / \mathrm{ml}$, a combination of true iron deficiency and ACD is more probable (11).

This study has several strengths but some limitations as well. First, this is a retrospective study, conducted in 17 different referral centers, where more severe IBD cases are followed up and further not all of them are abide by the anemia guidelines with the same way. Second, selection bias may exist because patients visit these centers and received treatment for anemia more frequently. What is more, the IBD activity assessment was made based on clinical scores (HBI, SCAAI) since the gold-standard, which is endoscopy, could not be applied in a retrospective study in 17 different IBD centers and furthermore fecal calprotectin is not yet widely available in Greece and the national health system does not reimburse IBD patients for this laboratory examination. On the other hand, this study included a large number of IBD patients and constitutes the first attempt to record anemia burden in Greek IBD patients and relevant treatment strategy. Moreover, a different classification of anemia based on the course of anemia (episodic, persistent and recurrent) together with the classic one (iron deficiency anemia, anemia of chronic disease and B12 or folic acid deficiency) were applied in order to depict more accurately the overall burden of anemia in IBD patients. Last, this study aimed to raise awareness towards anemia diagnosis and treatment that seems to be often neglected.

In conclusion, half of the Greek IBD patients present anemia during their disease course. One out of five patients present recurrent/persistent anemia despite the treatment for their primary disease. Risks factors for recurrent/persistent anemia are the presence of extraintestinal manifestations, IBD duration, IBD related surgeries and hospitalizations. In real life in referral Greek IBD centers, $77.9 \%$ of anemic patients receive anemia treatment with the majority of them receiving iron intravenously.

\section{Conclusions}

The frequency of anemia in IBD patients followed at Greek referral centers is approximately 50\%. Development of recurrent/persistent anemia may be observed in $20 \%$ of cases and is independently associated with presence of extraintestinal manifestations, IBD duration and IBD related surgeries and hospitalizations. Anemia treatment is administered in up to $4 / 5$ of anemia IBD patients with the majority of them receiving iron intravenously.

\footnotetext{
Abbreviations

IBD: Inflammatory bowel disease; UC: Ulcerative colitis; CD: Crohn's disease; IBDU: Inflammatory bowel disease unclassified; 5-ASA: 5-Sibdqaminosalicylic acid; ID: Iron deficiency; Hb: Hemoglobin; CRP: C-reactive protein; HBI: HarveyBradshaw score; SCCAI: Simple clinical colitis score; SIBDQ: Short inflammatory bowel disease questionnaire; WHO: World health organization; SD: Standard deviation; IQR: Interquartile range; Cl: Confidence interval; BMI: Body mass index; EIMs: Extraintesinal manifestations; IDA: Iron deficiency anemia; TSAT: Transferin saturation; ACD: Anemia of chronic disease; ECCO: European Chron's and colitis organization.
}

\section{Acknowledgements}

The members of the Hellenic group for the study of IBD: Kalliopi Foteinogiannopoulou, Konstantinos Karmiris, Georgios Axiaris, Magdalini Velegraki, Antonios Gklavas, Christina Kapizioni, Charalabos Karageorgos, Christina Kateri, Anastasia Katsoula, Georgios Kokkotis, Evgenia Koureta, Charikleia Lamouri, Panagiotis Markopoulos, Maria Palatianou, Ploutarchos Pastras, Konstantinos Fasoulas, Olga Giouleme, Evanthia Zampeli, Aggeliki Theodoropoulou, Georgios Theocharis, Konstantinos Thomopoulos, Pantelis Karatzas, Konstantinos H. Katsanos, Andreas Kapsoritakis, Anastasia Kourikou, Nikoleta Mathou, Spilios Manolakopoulos, Georgios Michalopoulos, Spyridon Michopoulos, Alexandros Boubonaris, Giorgos Bamias, Vasileios Papadopoulos, George Papatheodoridis, loannis Papaconstantinou, loannis Pachiadakis, Konstantinos Soufleris, Maria Tzouvala, Christos Triantos, Eftychia Tsironi, Dimitrios K. Christodoulou, and loannis E. Koutroubakis.

\section{Authors' contributions}

KF: Study design, data analysis, patient recruitment, data collection and writing up of the first draft of the paper. KK: patient recruitment, data collection. GA: patient recruitment, data collection. MV: patient recruitment, data collection. AG: patient recruitment, data collection. CK: patient recruitment, data collection. CK: patient recruitment, data collection. CK: patient recruitment, data collection. AK: patient recruitment, data collection. GK: patient recruitment, data collection. EK: patient recruitment, data collection. LC: patient recruitment, data collection. PM: patient recruitment, data collection. MP: patient recruitment, data collection. PP: patient recruitment, data collection. KF: patient recruitment, data collection. OG: patient recruitment, data collection. 
EZ: patient recruitment, data collection. AT: patient recruitment, data collection. GT: patient recruitment, data collection. KT: patient recruitment, data collection. PK: patient recruitment, data collection. KK: patient recruitment, data collection. AK: patient recruitment, data collection. AK: patient recruitment, data collection. NM: patient recruitment, data collection. SM: patient recruitment, data collection. GM: patient recruitment, data collection. SM: patient recruitment, data collection. AB: patient recruitment, data collection. GB: patient recruitment, data collection. VP: patient recruitment, data collection. GP: patient recruitment, data collection. IP: patient recruitment, data collection. IP: patient recruitment, data collection. KS: patient recruitment, data collection. MT: patient recruitment, data collection. CT: patient recruitment, data collection. ET: patient recruitment, data collection. DC: patient recruitment, data collection. IK: Study design, data analysis and correcting the first draft of the paper. All authors have read and approved the manuscript.

\section{Funding}

The study was partially supported by a grant of Vifor Pharma and a grant of the Hellenic team for the study of inflammatory bowel disease (EMIFNE).

\section{Availability of data and materials}

Data are available on request. Data underlying this article will be shared on reasonable request to the corresponding author.

\section{Declarations}

\section{Ethics approval and consent to participate}

The study was approved by the local ethics committee of University Hospital of Heraklion with the decision number 972/22-1-2019. For this type of study formal consent is not required.

\section{Consent for publication}

Not applicable.

\section{Competing interests}

loannis E. Koutroubakis: Advisory board member for Abbvie, Astelas, Genesis, Janssen, MSD, Pharmacosmos, Pfizer, Shire and Takeda; Speaker for AbbVie, Astelas, Genesis, Janssen, MSD, Takeda and Mylan; research support Abbvie and Ferring. Kalliopi Foteinogiannopoulou: no conflict of interest. Konstantinos Karmiris: received speaker fees from Abbvie, Aenorasis, Janssen, MSD, Pfizer and Takeda and consultancy or advisory board member fees from Abbvie, Amgen, Ferring, Galenica, Genesis, Janssen, MSD, Pfizer and Takeda. Konstantinos Thomopoulos: no conflict of interest. Olga Giouleme: no conflict of interest. Maria Tzouvala: no conflict of interest. Magdalini Velegraki: no conflict of interest. Nikoleta Mathou: no conflict of interest. Spilios Manolakopoulos: Gilead Sciences: research grands, Abbvie research grands, Pfizer: advisory, celltrion: research grands, shire plc/Takeda pharmaceutical: research grands. Andreas Kapsoritakis: no conflict of interest. Christos Triantos: no conflict of interest. Ploutarchos Pastras: no conflict of interest. George Papatheodoridis: advisor/lecturer for Abbvie, Dicerna, Elpen, Gilead, GlaxoSmithKline, Ipsen, Janssen, Merck Sharp \& Dohme, Roche, Spring Bank, Takeda; research grants Abbvie, Gilead; clinical trials: Abbvie, Astellas, Bayer, Boehringer Ingelheim, Bristol-Myers Squibb, Gilead, Janssen, Merck Sharp \& Dohme, Noorik, Novartis, Novo Nordisk, Regulus, Roche, Takeda. Evgenia Koureta: no conflict of interest. Christina Kapizioni: no conflict of interest. Georgios Michalopoulos: no conflict of interest. loannis Papaconstantinou: no conflict of interest. Antonios Gklavas: no conflict of interest. Lamouri Charikleia: no conflict of interest. Evanthia Zampeli: no conflict of interest. Georgios Kokkotis: no conflict of interest. Dimitrios K Christodoulou: advisor/lecturer for Abbvie, Janssen, Merck Sharp \& Dohme, Takeda, Enorasis, Genesis, Pfizer, Ferring. Spyridon Michopoulos: Advisor or Lecturer for Pfizer, Takeda, Abbvie, Ferring, MSD, Janssen. Giorgos Bamias: Advisor/lecturer for Janssen, Pfizer, Takeda, Abbvie, MSD, Mylan, Genesis Pharma, Adacyte Therapeutics, Amgen, Ferring, Cooper; Funding (Grants/ Honoraria): Pfizer, Takeda, Abbvie, Aenorasis; Research/Clinical Trials: Abbvie. Konstantinos Soufleris: Advisory Board Member, Lecturer for Abbvie, Amgen, Genesis Pharma, Janssen, MSD, Mylan, Pfizer, Takeda. Funding/Research Support/Clinical Trials: Abbvie, Celgene, Faran, Ferring, Janssen, Roche, Shire, Takeda.

\section{Author details}

${ }^{1}$ Gastroenterology Department, University Hospital of Heraklion, Medical School University of Crete, P.O. Box 1352, 71110 Heraklion, Crete, Greece. ${ }^{2}$ Department of Gastroenterology, Venizelio General Hospital, Heraklion, Greece. ${ }^{3}$ Department of Gastroenterology, General Hospital of Athens "Alexandra", Athens, Greece. ${ }^{4}$ 2nd Department of Surgery, Aretaieion Hospital, National and Kapodistrian University of Athens, Athens, Greece. ${ }^{5}$ Department of Gastroenterology, General Hospital of Piraeus "Tzaneio", Athens, Greece. ${ }^{6}$ Hepato-Gastroenterology/Endoscopy Unit, 2nd Department of Internal Medicine, National and Kapodistrian University of Athens, Athens General Hospital "Heppocratio", Athens, Greece. 'Department of Gastroenterology, University General Hospital of Larissa, Larissa, Greece. ${ }^{8}$ 2nd Internal Medicine Department, General Hospital of Thessaloniki "Ippokratio", Thessaloniki, Greece. ${ }^{9}$ Gastroenterology Unit, 3rd Academic Department of Internal Medicine, National and Kapodistrian Univeristy of Athens, "Sotiria" General Hospital, Athens, Greece. ${ }^{10}$ Department of Gastroenterology, National and Kapodistrian University of Athens, General Hospital of Athens "Laiko", Athens, Greece. ${ }^{11}$ Department of Gastroenterology, University General Hospital of loannina, loannina, Greece. ${ }^{12}$ Department of Gastroenterology, "Metaxa" General Anticancer Hospital of Piraeus, Piraeus, Greece. ${ }^{13}$ Department of Gastroenterology, General Hospital of Nikaia Piraeus "Ag. Panteleimon"-General Hospital Dytikis Attikis "Agia Varvara", Athens, Greece. ${ }^{14}$ Division of Gastroenterology, Department of Internal Medicine, University Hospital of Patras, Patras, Greece. ${ }^{15}$ Department of Gastroenterology-Oncology, Theageneio Cancer Hospital of Thessaloniki, Thessaloniki, Greece. ${ }^{16}$ Department of Gastroenterology, General Hospital of Nea Ionia "Konstantopoulio - Patision", Athens, Greece. ${ }^{17}$ Department of Gastroenterology, 424 General MilitaryHospital, Thessaloniki, Greece.

Received: 28 December 2020 Accepted: 23 May 2021

Published online: 29 June 2021

\section{References}

1. ECCO Country Member Profiles: Greece. https://www.ecco-ibd.eu/publi cations/ecco-news/ecco-country-member-profiles/item/ecco-countrymember-profiles-greece-2.html?category_id $=545$

2. Kulnigg S, Gasche C. Systematic review: managing anemia in Crohn's disease. Aliment Pharmacol Ther. 2006;24:1507-23.

3. Stein J, Hartmann F, Dignass AU. Diagnosis and management of iron deficiency anemia in patients with IBD. Nat Rev Gastroenterol Hepatol. 2010;7:599-610.

4. Woźniak M, Barańska M, Małecka-Panas E, Talar-Wojnarowska R. The prevalence, characteristics, and determinants of anaemia in newly diagnosed patients with inflammatory bowel disease. Gastroenterology Rev. 2019;14:39-47.

5. Koutroubakis IE, Ramos-Rivers C, Regueiro M, et al. Persistent or recurrent anemia is associated with severe and disabling inflammatory bowel disease. Clin Gastroenterol Hepatol. 2015;13:1760-6.

6. Wells CW, Lewis S, Barton JR, Corbett S. Effects of changes in hemoglobin level on quality of life and cognitive function in inflammatory bowel disease patients. Inflamm Bowel Dis. 2006;12:123-30.

7. Haas JD, Brownlie T. Iron deficiency and reduced work capacity: a critical review of the research to determine a causal relationship. J Nutr. 2001;131:676S-688S.

8. Rieder F, Paul G, Schnoy E, et al. Hemoglobin and hematocrit levels in the prediction of complicated Crohn's disease behaviorea cohort study. PLoS ONE. 2014;9:e104706.

9. Gasche C, Berstad A, Befrits R, et al. Guidelines on the diagnosis and management of iron deficiency and anemia in inflammatory bowel diseases. Inflamm Bowel Dis. 2007;13:1545-53.

10. WHO Haemoglobin concentrations for the diagnosis of anemia and assessment of severity. Vitamin and Mineral Nutrition Information System. Geneva, World Health Organization, 2011

11. Dignass AU, Gasche C, Bettenworth D, et al. European Consensus on the diagnosis and management of iron deficiency and anemia in inflammatory bowel diseases. J Crohn's Colitis. 2015;9:211-22.

12. Okam MM, Koch TA, Tran MH. Iron Supplementation, Response in Iron-Deficiency Anemia: Analysis of Five Trials. Am J Med 2017; 130:991 e1-991 e8 
13. Filmann N, Rey J, Schneeweiss S, et al. Prevalence of anemia in inflammatory bowel diseases in european countries: a systematic review and individual patient data meta-analysis. Inflamm Bowel Dis. 2014;20:936-45.

14. Gisbert JP, Gomollón F. Common misconceptions in the diagnosis and management of anemia in inflammatory bowel disease. Am J Gastroenterol. 2008;103:1299-307.

15. Bengi G, Keyvan H, Durmaz SB, Akpınar H. Frequency, types, and treatment of anemia in Turkish patients with inflammatory bowel disease. World J Gastroenterol. 2018:24:4186-96.

16. Pizzi LT, Weston CM, Goldfarb NI, et al. Impact of chronic conditions on quality of life in patients with inflammatory bowel disease. Inflamm Bowel Dis. 2006;12(1):47-52

17. Bergamaschi G, Di Sabatino A, Albertini R, et al. Prevalence and pathogenesis of anemia in inflammatory bowel disease Influence of anti-tumor necrosis factor alpha treatment. Haematologica. 2010;95:199-205.

18. Høivik ML, Reinisch W, Cvancarova M, Moum B; IBSEN study group. Anaemia in inflammatory bowel disease: a population-based 10-year follow-up. Aliment Pharmacol Ther. 2014;39:69-76

19. Kwon YH, Kim YJ. Pre-diagnostic clinical presentations and medical history prior to the diagnosis of inflammatory bowel disease in children. Pediatr Gastroenterol Hepatol Nutr. 2013;16:178-84.

20. Vegh Z, Kurti Z, Gonczi L, et al. Association of extraintestinal manifestations and anaemia with disease outcomes in patients with inflammatory bowel disease. Scand J Gastroenterol Gastroenterol. 2016;51:848-54.

21. Jimenez CM, Gasche C. Management of iron deficiency anaemia in inflammatory bowel disease. Acta Haematol. 2019;142:30-3.
22. Khan N, Patel D, Shah Y, Yang YX. Factors predicting testing and treatment of iron deficiency in a nationwide cohort of anemic UC patients. Inflamm Bowel Dis. 2016;22:2894-901.

23. Voegtlin M, Vavricka SR, Schoepfer AM, et al. Swiss IBD Cohort Study Prevalence of anaemia in inflammatory bowel disease in Switzerland: a cross-sectional study in patients from private practices and university hospitals. J Crohns Colitis. 2010;4:642-8.

24. Blumenstein I, Dignass A, Vollmer S, Klemm W, Weber-Mangal S, Stein J. Current practice in the diagnosis and management of IBD-associated anaemia and iron deficiency in Germany: The German AnaemIBD Study. J Crohns Colitis. 2014;8:1308-14.

25. SteinJ B. P, Befrits R, Gasche C, Gudehus M, Lerebours E, Anaemia management in patients with inflammatory bowel disease: routine practice across nine European countries. Eur J Gastroenterol Hepatol. 2013;25:1456-63.

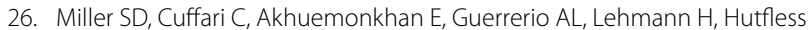
$\mathrm{S}$. Anemia screening, prevalence, and treatment in pediatric inflammatory bowel disease in the united states 2010-2014. Pediatr Gastroenterol Hepatol Nutr. 2019;22:152-61.

\section{Publisher's Note}

Springer Nature remains neutral with regard to jurisdictional claims in published maps and institutional affiliations.
Ready to submit your research? Choose BMC and benefit from:

- fast, convenient online submission

- thorough peer review by experienced researchers in your field

- rapid publication on acceptance

- support for research data, including large and complex data types

- gold Open Access which fosters wider collaboration and increased citations

- maximum visibility for your research: over $100 \mathrm{M}$ website views per year

At BMC, research is always in progress.

Learn more biomedcentral.com/submissions 